\title{
The effect of vitamin E-bonded polysulfone membrane dialyzer on a new oxidative lipid marker
}

\author{
Yuki Kitamura $\cdot$ Kumi Kamimura \\ Noriko Yoshioka $\cdot$ Yoko Hosotani $\cdot$ Kenji Tsuchida $\cdot$ \\ Masahide Koremoto $\cdot$ Jun Minakuchi
}

Received: 27 July 2012/Accepted: 21 January 2013/Published online: 10 February 2013

(C) The Japanese Society for Artificial Organs 2013

\begin{abstract}
The use of vitamin E-bonded cellulose membrane dialyzers has been reported to cause a decrease in oxidative lipid marker levels (Nakai et al., Ther Apher Dial 14:505-540, 1; Nakai et al., J Jpn Soc Dial Ther 45:1-47, 2; Mashiba et al., Arterioscler Thromb Vasc Biol 21:1801-1808, 3). However, few studies have identified this effect with vitamin E-bonded polysulfone membranes, and no studies report the same effect on alpha (1) antitrypsin-LDL complex, a new oxidative lipid marker. This prompted us to examine the influence of use of VPS-HA vitamin E-bonded polysulfone high-flux membrane dialyzers on this new oxidative lipid marker. The subjects were 17 patients who had been dialyzed with VPS-HA for 12 months. The subjects' baseline characteristics were as follows. Their average age was $65.6 \pm 13.1$ years, comprising 8 males and 9 females; hemodialysis vintage was $83.8 \pm 85.4$ months. Eight had chronic glomerular nephropathy and five had diabetic nephropathy. The primary outcome was defined as alpha (1) antitrypsin-LDL
\end{abstract}

Y. Kitamura $\cdot$ K. Tsuchida $\cdot$ J. Minakuchi

Department of Kidney Disease (Dialysis and Kidney

Transplantation), Kawashima Hospital, Tokushima, Japan

Y. Kitamura $(\bowtie)$

Department of Urology, National Hospital Organization Kyoto

Medical Center, 1-1 Mukaihata-cho, Fukakusa, Fushimi-ku,

Kyoto 612-8555, Japan

e-mail: ykitamur@kyotolan.hosp.go.jp

K. Kamimura $\cdot$ N. Yoshioka $\cdot$ Y. Hosotani

Clinical Engineering, Kawashima Hospital, Tokushima, Japan

M. Koremoto $(\square)$

Scientific and Technical Affairs Department, Asahi Kasei

Medical Co., Ltd., 1-105 Kanda Jinbocho, Chiyoda-ku, Tokyo

101-8101, Japan

e-mail: m-koremoto@umin.org complex level after 12 months, as a post-study using VPSHA. Secondary outcomes included triglycerides, total cholesterol, HDL cholesterol and LDL cholesterol levels. The data were analyzed pre-study and after 3, 6, 9 and 12 months for alpha (1) antitrypsin-LDL complex, and pre-study and post-study for the other indicators. Twelve months after switching to VPS-HA, alpha (1) antitrypsinLDL complex, total cholesterol and LDL cholesterol had significantly decreased. Triglycerides and HDL cholesterol had not significantly changed. Hemodialysis therapy with VPS-HA was shown to decrease alpha (1) antitrypsin-LDL complex, an index of oxidative stress, and also to decrease some lipid markers.

Keywords Vitamin E-bonded polysulfone membrane dialyzer · Alpha (1) antitrypsin-LDL complex $\cdot$ LDL cholesterol

\section{Introduction}

An overview of regular dialysis treatment in Japan as of 31 December 2008 reported by the Japanese Society for Dialysis Therapy showed that more than half of hemodialysis patients were being dialyzed with high-flux polysulfone (PS) membrane [1]. Of the deaths among long-term hemodialysis patients, $39.8 \%$ were reported to be due to cardiovascular disorders (heart failure, cerebrovascular disorders, myocardial infarction) centered on the heart [2].

Recent reports suggest alpha (1) antitrypsin (AT) lowdensity lipoprotein complex [alpha (1) AT-LDL complex] [3], which promotes arteriosclerosis, to be implicated in oxidative LDL in circulatory system diseases. Alpha (1) AT-LDL complex is comprised of alpha (1) AT and LDL cholesterol and appears to be a type of oxidative LDL that 
undergoes oxidative degeneration because of lipids accumulated by macrophages in atherosclerotic lesions [3]. Alpha (1) AT-LDL complex may thus be a useful marker of arteriosclerosis. It has been reported that activation of complements, discharge of granulocytic elastase, lipid peroxidation of red blood cell membranes, production of oxidative LDL and coagulation in the dialyzer are suppressed when using vitamin E-bonded membrane dialyzers [4-7]. However, few patients dialyzed with vitamin E-bonded membrane dialyzers have been studied, and their clinical effectiveness is thus unknown.

We focused on alpha (1) AT-LDL complex in oxidative LDL, which is related to circulatory system malfunction, and examined lipid markers using a vitamin E-bonded high-flux PS membrane dialyzer.

\section{Materials and methods}

This study was approved by the Kawashima Hospital Ethics Committee on Human Research. All patients gave their prior informed consent to this study. Seventeen patients using conventional dialyzers were enrolled as subjects of this study. The baseline characteristics of the subjects were as follows: average age $65.6 \pm 13.1$ (44-84) years; gender, 8 males and 9 females; average hemodialysis period, $83.8 \pm 85.4$ (7-336) months; primary disease: 6 with chronic glomerulonephritis, 5 with diabetic nephropathy, 2 with nephrosclerosis and 4 with other conditions. All subjects had been dialyzed with conventional dialyzers before switching to VPS-HA vitamin E-bonded high-flux polysulfone membrane dialyzer for 12 months.

Alpha (1) AT/LDL complex was assayed at 0 months, 1 month, 3 months, 6 months, 9 months and 12 months. Triglycerides (TG), total cholesterol (T-cho), HDL cholesterol (HDL) and LDL cholesterol (LDL) were measured at 0 and 12 months.

The levels of alpha (1) AT-LDL complex were measured in the following way. The isolation of VLDL plus LDL from serum was performed as described previously [8]. A $1.5-\mathrm{mL}$ aliquot of polyanion solution $(0.053 \mathrm{M}$ $\mathrm{MnCl}_{2}$ and $0.002 \%$ heparin sodium) was added to $50 \mu \mathrm{L}$ of serum. The mixture was incubated for $30 \mathrm{~min}$ at room temperature, then centrifuged for $15 \mathrm{~min}$ at $2,000 \times g$. The supernatant was decanted and the precipitate dissolved in $250 \mu \mathrm{L}$ of $2.5 \% \mathrm{NaCl}$. Enzyme-linked immunoassay was then carried out: anti-human AT antibody (Dako, Denmark) was dissolved in $50 \mathrm{mmol} / \mathrm{L}$ Tris- $\mathrm{HCl}$ buffer $(\mathrm{pH}$ 8.4) to a final concentration of $5 \mu \mathrm{g} / \mathrm{mL}$. A $100-\mu \mathrm{L}$ aliquot of the solution was then placed in each well of a 96-well microplate array (Corning Inc., USA) and then immobilized overnight at $4{ }^{\circ} \mathrm{C}$. The microplates were rinsed three times with PBS containing $0.05 \%$ Tween 20, and the reaction was blocked with $1 \%$ casein in TBS $(100 \mathrm{mmol} / \mathrm{l}$ Tris- $\mathrm{HCl}$ buffer, $150 \mathrm{mmol} / \mathrm{L} \mathrm{NaCl}$, at $\mathrm{pH} \mathrm{8.0)}$ at $100 \mu \mathrm{L} /$ well. The precipitate samples $(50 \mu \mathrm{L} /$ well $)$ were then added. The microplates were incubated for $2 \mathrm{~h}$ at $37{ }^{\circ} \mathrm{C}$ and then rinsed five times with PBS containing $0.005 \%$ Tween 20. As the secondary antibody, biotinylated Fab' anti-human apoB monoclonal antibody (Ikagaku Co., Ltd., Japan) was diluted to $1 \mu \mathrm{g} / \mathrm{mL}$ in $1 \%$ casein TBS and then placed in the microplates at $100 \mu \mathrm{L} /$ well. The mixture in the microplates was allowed to react for $1 \mathrm{~h}$ at $37^{\circ} \mathrm{C}$. The microplates were then rinsed five times with PBS containing $0.005 \%$ Tween 20. Peroxidase-labeled avidin (Vector Laboratories Inc., USA), as the tertiary antibody, was diluted 20,000-fold in $1 \%$ casein TBS and added to the microplates at $100 \mu \mathrm{L} /$ well. The mixture was then allowed to react for $30 \mathrm{~min}$ at $37^{\circ} \mathrm{C}$. The microplates were rinsed five times with PBS containing $0.005 \%$ Tween 20. The residual activity was measured as the difference in optical absorbance between 450 and $620 \mathrm{~nm}$ after adding $100 \mu \mathrm{L}$ of TMB Microwell Peroxidase Substrate (KPL Inc., USA) to each well. The reaction was terminated by adding $1 \mathrm{~mol} / \mathrm{L}$ phosphoric acid. Serum AT-LDL levels were calculated as a function of LDL after determining LDL levels using the reagent measurement kit [3].

We determined that since hypolipidemic drugs risked acting as confounding factors, all patients should maintain the same dosages and types of hypolipidemic drugs they were being prescribed before the study began.

To eliminate the influence on the data of confounding factors, all patients also maintained the same hemodialysis conditions before starting to use VPS-HA as an interventional dialyzer. We regarded the following as potential confounding factors: dry weight, HD dosage (except for hemodialysis sessions with symptoms), sodium and calcium concentration of the dialysate, and dialysate temperature.

The HD conditions were as follows. HD sessions were performed thrice-weekly for $4 \mathrm{~h}$ at a blood flow rate of $245.9 \pm 12.8$ (200-250) $\mathrm{mL} / \mathrm{min}$, conforming to standard Japanese hemodialysis conditions. Dialysate with sodium, calcium and acetate concentrations of approximately 140 , 3 and $10 \mathrm{mEq} / \mathrm{L}$, respectively, was supplied by a centrally supplied dialysate system at a flow rate of $500 \mathrm{~mL} / \mathrm{min}$. The water for preparation of the dialysate was purified using a reverse osmotic filter, an ultrafiltrate filter and an endotoxin retention filter.

All the subjects had been undergoing hemodialysis using the following conventional dialyzers. Six patients had used EK (ethylene vinyl alcohol, Kawasumi Laboratories Inc., Tokyo, Japan), four patients had used BG-PQ (polymethyl methacrylate, Toray, Tokyo, Japan), four patients had used FB-U beta (cellulose triacetate, Nipro, Osaka, Japan), one patient had used CX-U (polysulfone, 
Toray, Tokyo, Japan), one patient had used PES-D alpha (polyethersulfone, Nipro, Osaka, Japan), and one patient had used FDY-GW (polyethersulfone polymer alloy, Nikkiso, Tokyo, Japan). The surface area of the conventional dialyzers' membrane was $1.68 \pm 0.16 \mathrm{~m}^{2}$.

Statistical analyses were performed using XLSTAT (ver. 2011, Addinsoft SARL, Paris, France). Primary and secondary outcome measures were compared using the Mann-Whitney $U$ test and the Tukey-Kramer post hoc multiple comparison test. A two-tailed $P<0.05$ was regarded as statistically significant.

\section{Results}

The ultrafiltration volume, dialysate temperature and room temperature were $2.5 \pm 0.9(1.17-4.45) \mathrm{L} /$ session, $36.3 \pm 0.4(35.0-36.5){ }^{\circ} \mathrm{C}$ and $27.8 \pm 0.1(27.7-27.8){ }^{\circ} \mathrm{C}$ through the research period, respectively. Prior to the study, all the subjects were being administered one or more of the following antihypertensive medications: calcium channel blockers (8 patients), angiotensin-converting enzyme inhibitors, alpha-blockers (1 patient), beta-blockers (1 patient), angiotensin receptor blockers (3 patients) and other types (1 patient). As ESAs, epoetin beta or darbepoetin alpha was used.

Before the study, conventional dialyzers had been used for $6.0 \pm 1.4$ (3.4-7.8) months. During the present study, the dialyzer membrane area was $1.64 \pm 0.19 \mathrm{~m}^{2}$, since conventional $1.6 \mathrm{~m}^{2}$ dialyzers were replaced with VPS-HA dialyzers that have an area of $1.5 \mathrm{~m}^{2}$. There were six patients from class III to IV and one patient from class V to IV according to the Japanese reimbursement system. Thirteen patients had never been administered hypolipidemic drugs. One patient was administered hypolipidemic drugs before and during the study. Two patients were given decreased doses of hypolipidemic drugs during VPS-HA treatment.

Changes in each lipid marker were compared using VPS-HA. Alpha (1) AT-LDL complex, total cholesterol and LDL cholesterol were significantly decreased at 12 months (Figs. 1, 2, 3, respectively). At 12 months, the value of alpha (1) AT-LDL complex had changed from $2.40 \pm 0.50$ to $1.48 \pm 0.45 \mathrm{mg} / \mathrm{mL}$, that of total cholesterol had changed from $188.2 \pm 37.8$ to $161.2 \pm 30.2 \mathrm{mg} /$ $\mathrm{mL}$ and that of LDL cholesterol had changed from $103.0 \pm 23.6$ to $90.6 \pm 18.6 \mathrm{mg} / \mathrm{mL}$. Triglycerides did not significantly change from $165.6 \pm 73.1$ to $136.8 \pm 65.9$ $\mathrm{mg} / \mathrm{mL}$ at 12 months (data not shown), and HDL cholesterol did not significantly change from $46.0 \pm 19.9$ to $38.2 \pm 14.3 \mathrm{mg} / \mathrm{mL}$ at 12 months (data not shown). Alpha (1) AT-LDL complex decreased significantly and steadily (Fig. 4, $2.40 \pm 0.50$ at 0 months, $2.17 \pm 0.52$ at 1 month, $1.70 \pm 0.46$ at 3 months, $2.04 \pm 0.60$ at 6 months, $1.66 \pm 0.62$ at 9 months and $1.48 \pm 0.45$ at 12 months).

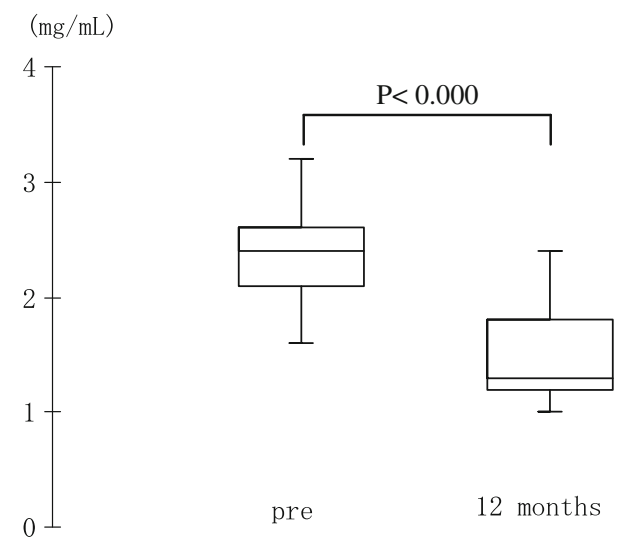

Fig. 1 Box and whisker plots of alpha (1) antitrypsin-LDL complex between pre-using and post-using VPS-HA. Statistical analysis was performed using the Mann-Whitney $U$ test

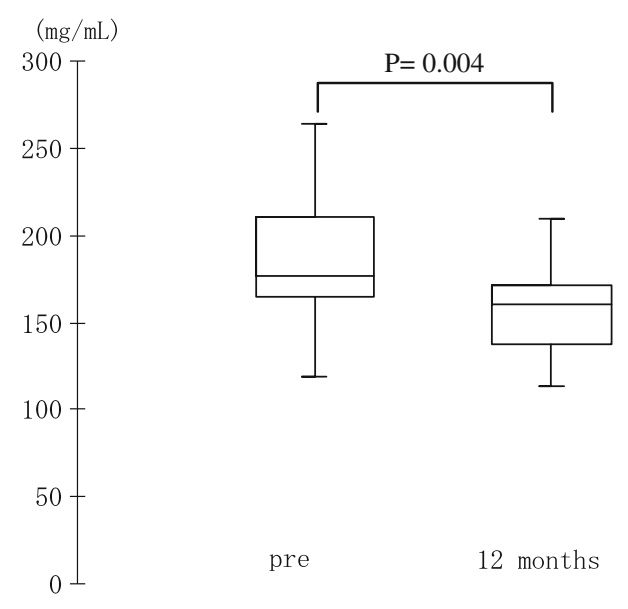

Fig. 2 Box and whisker plots of total cholesterol between pre-using and post-using VPS-HA. Statistical analysis was performed using the Mann-Whitney $U$ test

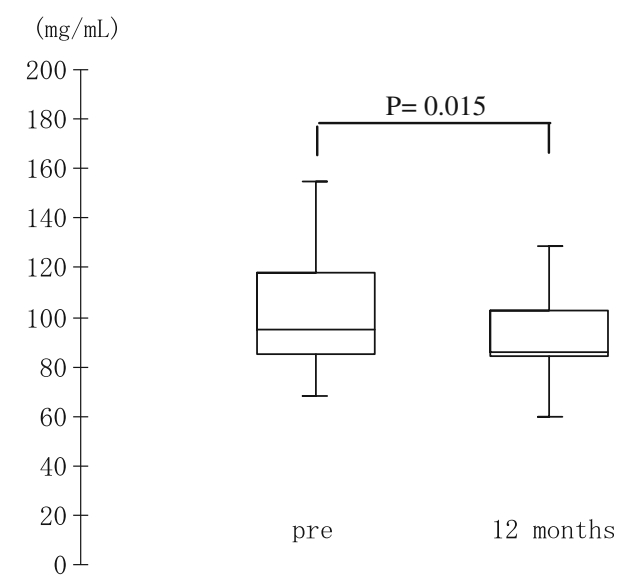

Fig. 3 Box and whisker plots of LDL cholesterol between pre-using and post-using VPS-HA. Statistical analysis was performed using the Mann-Whitney $U$ test 


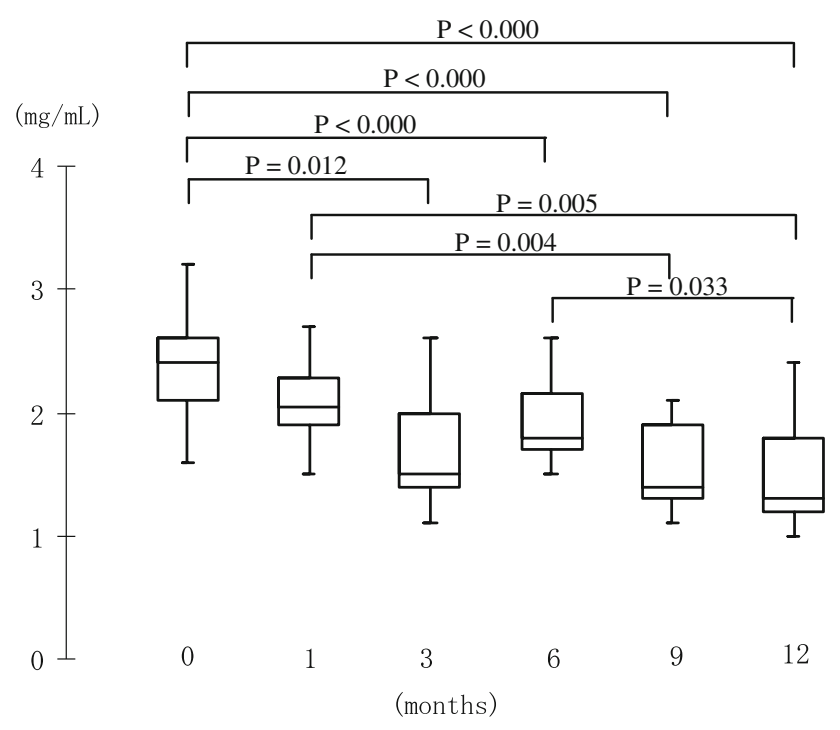

Fig. 4 Box and whisker plots of alpha (1) antitrypsin-LDL complex using VPS-HA. Statistical analysis was performed by the TukeyKramer post-hoc multiple comparison test. $P<0.05$ is regarded as statistically significant

We tried to obtain additional clinical data for pre- and post-dialysis serum concentration and fluid waste concentration of each lipid marker. The values for alpha (1) AT LDL complex were $0.0 \mathrm{mg} / \mathrm{mL}$ in the fluid waste, $1.3 \pm$ $0.4 \mathrm{mg} / \mathrm{mL}$ in the pre-dialysis serum and $2.3 \pm 0.6 \mathrm{mg} / \mathrm{mL}$ in the post-dialysis serum. Similarly, those for total cholesterol were $0.0 \mathrm{mg} / \mathrm{mL}$ in fluid waste, $170.9 \pm 35.1 \mathrm{mg} / \mathrm{mL}$ in the pre-dialysis serum and $204.6 \pm 48.3 \mathrm{mg} / \mathrm{mL}$ in the post-dialysis serum. In addition, those for LDL cholesterol were $0.0 \mathrm{mg} / \mathrm{mL}$ in fluid waste, $101.2 \pm 26.5 \mathrm{mg} / \mathrm{mL}$ in the pre-dialysis serum and $126.1 \pm 38.0 \mathrm{mg} / \mathrm{mL}$ in the postdialysis serum.

\section{Discussion}

The vitamin E-bonded membrane, as well as the conventional membrane, has a diffusion layer [9]. It thus appears that both membranes inhibit the adsorption of serum protein via the same mechanism. There are few reports on vitamin E-bonded PS membrane dialyzers, except on the antioxidant effects of vitamin E-bonded low-flux cellulose membranes. In our present study, alpha (1) AT-LDL complex, used as a lipid marker and an index of oxidative stress, significantly decreased when using VPS-HA.

The molecular weight of alpha (1) antitrypsin-LDL complex is around $660 \mathrm{kDa}$, that of LDL cholesterol is around $2,000 \mathrm{kDa}$ and that of total cholesterol was estimated to be greater than $660 \mathrm{kDa}$. In the results of the additional clinical trial, no lipid markers were detected in the fluid waste. All lipid markers showed an elevation in serum concentration from pre-dialysis to post-dialysis. Because the molecular weights of all lipid markers prevent them from passing through the membrane fiber pores, we concluded that all lipids markers were concentrated by hemodialysis therapy. We calculated the value of each lipid marker by dividing it by its value in body fluid. The results showed the front-back ratio of each lipid marker to exceed 1.0. We concluded that this is not due to a mechanism such as adsorption estimated from the values of the front-back ratio of each lipid marker and leak out in the waste fluid, but due to another mechanism.

It has been suggested that the radical chain reaction is related to the peroxidation of lipids [10]. We conclude that the mechanism of decrease does not depend on dialysis (diffusion and filtration) or adsorption: another mechanism is at work here. Satoh et al. [7] and Morimoto et al. [11] have reported a decrease in MDA and oxidative LDL with the use of conventional vitamin E-bonded membrane dialyzers. We therefore conclude that the mechanism of alpha (1) antitrypsin-LDL complex depends on the antioxidant status, by way of protecting against the oxidation of lipids during hemodialysis. There are no reports on administration of hypolipidemic drugs to hemodialysis patients even when they are treated with alpha (1) antitrypsin-LDL complex instead of vitamin E-non-bonded membrane dialyzer. When VPS-HA is used, it appears to act as a radical scavenger that stops the radical chain reaction. It is the vitamin E-bonded membrane that acts in this way, since vitamin $\mathrm{E}$ reacts with lipid peroxide radicals. It appears that oxidative lipid markers of oxidative stress decrease because the vitamin E-bonded membrane is involved in stopping the radical chain reaction inside the patient's body. Alpha (1) AT-LDL complex as an oxidative stress factor also decreased in this study. Although it was reported in the JOMS Study that alpha (1) AT-LDL complex is not related to metabolic syndrome complex, oxidation LDL for alpha (1) AT-LDL complex is likely to be a future focus of interest [12]. We thus believe that hemodialysis therapy using VPS-HA, a radical scavenging membrane dialyzer, significantly decreases oxidative stress, as evidenced by lower levels of alpha (1) AT-LDL complex in hemodialysis patients. A recent study by Koremoto et al. [13] describes improved intradialytic hypotension in diabetic hemodialysis patients using VPS-HA. We plan to investigate the relationship between oxidative lipid markers specific to arteriosclerosis and those specific to arteriosclerosis and intradialytic hypotension, if they can be identified, in a subsequent long-term study of the relationship between oxidative lipid markers and intradialytic hypotension.

\section{Conclusion}

VPS-HA significantly decreased alpha (1) AT-LDL complex as an oxidative stress marker. LDL cholesterol and total cholesterol also decreased. 
Acknowledgments We thank Shinichi Mashiba and Kazuhiko Kotani for help with the analysis of the alpha (1) AT-LDL complex. This research was supported by Asahi Kasei Medical Co., Ltd.

Conflict of interest Masahide Koremoto is an employee of Asahi Kasei Medical Co., Ltd. There is no conflict of interest for the other authors. Financial disclosure: this research was supported by Asahi Kasei Medical Co., Ltd.

\section{References}

1. Nakai S, Suzuki K, Masakane I, Wada A, Itami N, Ogata S, Kimata N, Shigematsu T, Shinoda T, Syouji T, Taniguchi M, Tsuchida K, Nakamoto H, Nishi S, Nishi H, Hashimoto S, Hasegawa T, Hanafusa N, Hamano T, Fujii N, Marubayashi S, Morita O, Yamagata K, Wakai K, Watanabe Y, Iseki K, Tsubakihara Y. Overview of regular dialysis treatment in Japan (as of 31 December 2008). Ther Apher Dial. 2010;14:505-40.

2. Nakai S, Iseki K, Itami N, Ogata S, Kazama JJ, Kimata N, Shigematsu T, Shinoda T, Shoji T, Suzuki K, Taniguchi M, Tsuchida K, Nakamoto H, Nishi H, Hashimoto S, Hasegawa T, Hanafusa N, Hamano T, Fujii N, Masakane I, Marubayashi S, Morita O, Yamagata K, Wakai K, Wada A, Watanabe Y, Tsubakihara Y. An overview of regular dialysis treatment in Japan (as of 31 December 2010) J Jpn Soc Dial Ther. 2012;45:1-47 (in Japanese).

3. Mashiba S, Wada Y, Takeya M, Sugiyama A, Hamakubo T, Nakamura A, Noguchi N, Niki E, Izumi A, Kobayashi M, Uchida $\mathrm{K}$, Kodama T. In vivo complex formation of alpha 1-antitrypsin and LDL. Arterioscler Thromb Vasc Biol. 2001;21:1801-8.

4. Kuragano T, Kida A, Itoh K, Furuta A, Yamamoto S, Tokuyama M, Hata R, Nanami M, Otaki Y, Hasuike Y, Izumi M, Nakanishi $\mathrm{T}$. The anti-oxidant effect of acetate-free-biofiltration (AFB) with vitamin E coated polysulfone membrane (VPS). Vitamembrane. 2008;8:35-40 (in Japanese).
5. Amore A, Cirina P, Bonaudo R, Conti G, Chiesa M, Coppo R. Bicarbonate dialysis, unlike acetate-free biofiltration, triggers mediators of inflammation and apoptosis in endothelial and smooth muscle cells. J Nephrol. 2006;19:57-64.

6. Amore A, Cirina P, Mitola S, Peruzzi L, Bonaudo R, Gianoglio B, Coppo R. Acetate intolerance is mediated by enhanced synthesis of nitric oxide by endothelial cells. J Am Soc Nephrol. 1997;8:1431-6.

7. Satoh M, Yamasaki Y, Nagake Y, Kasahara J, Hashimoto M, Nakanishi N, Makino H. Oxidative stress is decreased by the long-term use of vitamin $\mathrm{E}$ coated dialysis filters. Kidney Int. 2001;59:1943-50.

8. Burstein M, Scholnick HR, Morfin R. Rapid method for the isolation of lipoproteins from human serum by precipitation with polyanions. J Lipid Res. 1970;11:583-95.

9. Matsumoto Y. Vitamin E-bonded polysulfone membrane dialyzer. In: Takezawa S, Arakawa M, Fukuda M, editors. High performance dialyzer, vol. 1; 2008. p. 71-6 (in Japanese).

10. Naito Y. Radical oxygen species (ROS). In: Kurabayashi M, Yamagishi S, editors. Oxidative stress navigator, vol. 1; 2005. p. 28-9 (in Japanese).

11. Morimoto H, Nakao K, Fukuoka K, Sarai A, Yano A, Kihara T, Fukuda S, Wada J, Makino H. Long-term use of vitamin E-coated polysulfone membrane reduces oxidative stress markers in haemodialysis patients. Nephrol Dial Transplant. 2005;20:2775-82.

12. Kotani K, Satoh N, Kato Y, Araki R, Koyama K, Okajima T, Tanabe M, Oishi M, Yamakage H, Yamada K, Hattori M, Shimatsu A, Japan Obesity and Metabolic Syndrome Study Group. A novel oxidized low-density lipoprotein marker, serum amyloid A-LDL, is associated with obesity and the metabolic syndrome. Atherosclerosis. 2009;204:526-31.

13. Koremoto M, Takahara N, Takahashi M, Okada Y, Satoh K, Kimura T, Hirai T, Ebihara I, Nagasaku D, Miyata S, Maniwa S, Kouzuma T, Arimura T, Kamei J. Improvement of intradialytic hypotension in diabetic hemodialysis patients using vitamin E-bonded polysulfone membrane dialyzers. Artif Organs. 2012;36: 901-10. 